\title{
Hybrid two-stage repair of Stanford A dissection with visceral or peripheral malperfusion
}

\author{
Zanxin Wang ${ }^{1,2}$, Xianmian Zhuang ${ }^{1}$, Bailang Chen ${ }^{1}$, Junmin Wen ${ }^{3}$ and Minxin Wei ${ }^{1,2^{*}}$
}

\begin{abstract}
Background: The present study aimed to evaluate the effect of two-stage hybrid aortic repair at the distal aorta of Stanford A dissection with malperfusion.

Methods: This retrospective case series included 20 patients with Stanford A dissection administered two-stage thoracic endovascular aortic repair (TEVAR) about 1 month after central repair because of visceral or limb malperfusion. The patients were examined by computed tomography (CT) angiography at 3, 6, 12 and 24 months after operation. Recovery of malperfusion and true lumen index were evaluated during follow-up.

Results: Twenty patients underwent two-stage hybrid aortic repair, including 11 males and 9 females. The followup time was $24 \pm 7$ months. No intervention-related complications were observed, including stent graft-induced new re-entry tears, death, stroke and spinal cord injury. Malperfusion in all cases was corrected. The true lumen was not enlarged enough 1 month after the first surgery. Thrombosis of the false lumen was observed around the elephant trunk at the carina level and the celiac artery. Three months after second stage TEVAR, the false lumen thrombosis was resorbed; in addition, the trunk was fully expanded at the carina level, and the true lumen was enlarged at the celiac artery.

Conclusions: Two-stage hybrid aortic repair for residual true lumen in the distal aorta 1 month after initial surgery is helpful for descending aorta remodeling and effective in treating malperfusion. This procedure may be a good option for patients suffering from Stanford A dissection with small true lumen in the distal aorta and malperfusion.
\end{abstract}

Keywords: Aortic dissection, Malperfusion, Hybrid procedure, Thoracic endovascular aortic repair

\section{Background}

Stanford A aortic dissection is an acute condition characterized by the disruption of the thoracic aortic media layer caused by intramural bleeding separating the aortic wall layers; it leads to the formation of true and false lumen with or without communication [1-4]. Open surgery (total arch

\footnotetext{
* Correspondence: Weimx@hku-szh.org

'Department of Cardiac Surgery, Fuwai Hospital Chinese Academy of Medical Sciences, Shenzhen, Guangdong, People's Republic of China

${ }^{2}$ Department of Cardiac Surgery, The University of Hong Kong - Shenzhen Hospital, Shenzhen, Guangdong, People's Republic of China

Full list of author information is available at the end of the article
}

replacement combined with elephant trunk stent implantation) is routinely applied in most cardiac centers. However, it is only the first step aiming to avoid lethal complications [5]. Small true lumen in distal descending aorta leading to malperfusion is a potential risk factor for poor long-term prognosis [6].

The malperfusion syndrome can affect different vascular beds depending upon the exact location of the aortic tear: spinal cord, visceral, renal, and lower extremities $[7,8]$. It is found in $20-40 \%$ of patients with Stanford A aortic dissection. Nearly $20 \%$ of these individuals require additional revascularization $[9,10]$.

C C The Author(s). 2020 Open Access This article is licensed under a Creative Commons Attribution 4.0 International License, which permits use, sharing, adaptation, distribution and reproduction in any medium or format, as long as you give appropriate credit to the original author(s) and the source, provide a link to the Creative Commons licence, and indicate if changes were made. The images or other third party material in this article are included in the article's Creative Commons licence, unless indicated otherwise in a credit line to the material. If material is not included in the article's Creative Commons licence and your intended use is not permitted by statutory regulation or exceeds the permitted use, you will need to obtain permission directly from the copyright holder. To view a copy of this licence, visit http://creativecommons.org/licenses/by/4.0/. The Creative Commons Public Domain Dedication waiver (http://creativecommons.org/publicdomain/zero/1.0/) applies to the data made available in this article, unless otherwise stated in a credit line to the data. 
The malperfusion syndrome may be complicated by a wide variety of symptoms. Nevertheless, early diagnosis is important in avoiding damage to organs and the subsequent inflammatory cascade that can affect the treatment success and patient prognosis [7, 8].

The hybrid procedure uses thoracic endovascular aortic repair (TEVAR) of distal descending aorta. Type III hybrid aortic repair, which encompasses total arch replacement with the descending elephant trunk, combined with second stage TEVAR, is indicated for acute aortic dissection with malperfusion or rupture [11-17]. Studies on second stage repair of distal residual aorta have prompted surgeons to seek the optimal time and location for performing TEVAR and avoiding complications. Therefore, the present retrospective study aimed to describe our experience and evaluate the effectiveness of Type III hybrid aortic repair at the distal aorta of acute Stanford type A aortic dissection with malperfusion.

\section{Methods \\ Patients}

This was a retrospective study. A total of 132 patients with Stanford A aortic dissection from January 2015 to December 2017 were treated in Fuwai Hospital Chinese Academy of Medical Sciences Shenzhen and Tianjin Medical University General hospital. Twenty of them underwent second stage TEVAR because of limb or visceral malperfusion, diagnosed both by clinical symptoms and radiographic findings.

This study was approved by the ethics committees of Fuwai Hospital Chinese Academy of Medical Sciences Shenzhen and Tianjin Medical University General Hospital. The need for individual consent was waived by the committees because of the retrospective nature of the study.

Malperfusion was reflected by symptoms or signs of compromised blood flow to a limb or visceral vessels. To diagnose limb malperfusion, pulse deficit was necessary, and computed tomography (CT) angiography was used to corroborate this clinical findings. Visceral malperfusion was determined via a combination of clinical and radiographic factors, including radiographic evidence of flow obstruction with clinical indicators of ischemia to the abdominal viscera such as melena or abdominal pain with distention.

\section{Surgical procedures}

The diagnosis of acute Stanford A dissection was made by CT angiography [1].

The initial repair of acute Stanford A dissection was open surgery by the frozen elephant trunk (FET) technique: total arch replacement combined with elephant trunk stent implantation. All patients underwent CT scan within 3 months after the initial repair depending on the recovery of the distal aorta and malperfusion. Those still with malperfusion received TEVAR using a standardized protocol [18-21].

TEVAR was deployed using a graft landing zone of at least $2 \mathrm{~cm}$ via the retrograde femoral approach. The stent-graft diameter exceeded the diameter of the landing zone by at least $10-15 \%$. All TEVAR procedures were performed under local anesthesia with invasive blood pressure monitoring.

\section{Follow-up}

The patients were followed up at 3, 6, and 12 months, and then annually at the outpatient department. Aortic $\mathrm{CT}$ angiography was performed at each follow-up.

Total aortic diameter (adventitia to adventitia), true lumen diameter, and false lumen diameter were measured on CT scans at the celiac artery. The true lumen index was the true lumen diameter relative to total aortic diameter, and was calculated to evaluate the impact of second stage TEVAR on distal aorta remodeling [16].

\section{Statistical analysis}

All statistical analyses were performed with SPSS 25.0 (IBM, Armonk, NY, USA). Continuous variables are mean \pm standard deviation (SD), and were compared by the Student's $t$ test. Categorical variables were displayed as frequency (\%) and analyzed by the chi-square test or fisher's exact test. Repeated measures analysis of variance was performed for intragroup comparisons at different time points. Two-sided $P<0.05$ was considered statistically significant.

\section{Results}

Twenty patients underwent second stage TEVAR (Fig. 1), including 11 males and 9 females. The average age was $45.1 \pm 12.2$ years. Baseline and surgical information is shown in Table 1. The reasons for TEVAR are listed in Table 2. There were no death, stroke, or spinal cord injury cases during or after TEVAR.

One patient had failed TEVAR, because the elephant trunk was inserted into the false lumen. Aortic angiography showed the true lumen was constricted and very small. Blood flow in main vessels of the abdominal organs was normal. The descending aorta was not enlarged, and the patient had no complaint (Fig. 2). Follow-up is still going on. Further intervention will be performed later. His data are not shown in Table 2.

In another case, the distal part of the elephant trunk was inserted into an ulcer of the descending aorta in the first surgery (Fig. 3a). This was found by CT angiography 2 weeks after the operation. With limb malperfusion, second stage TEVAR was 


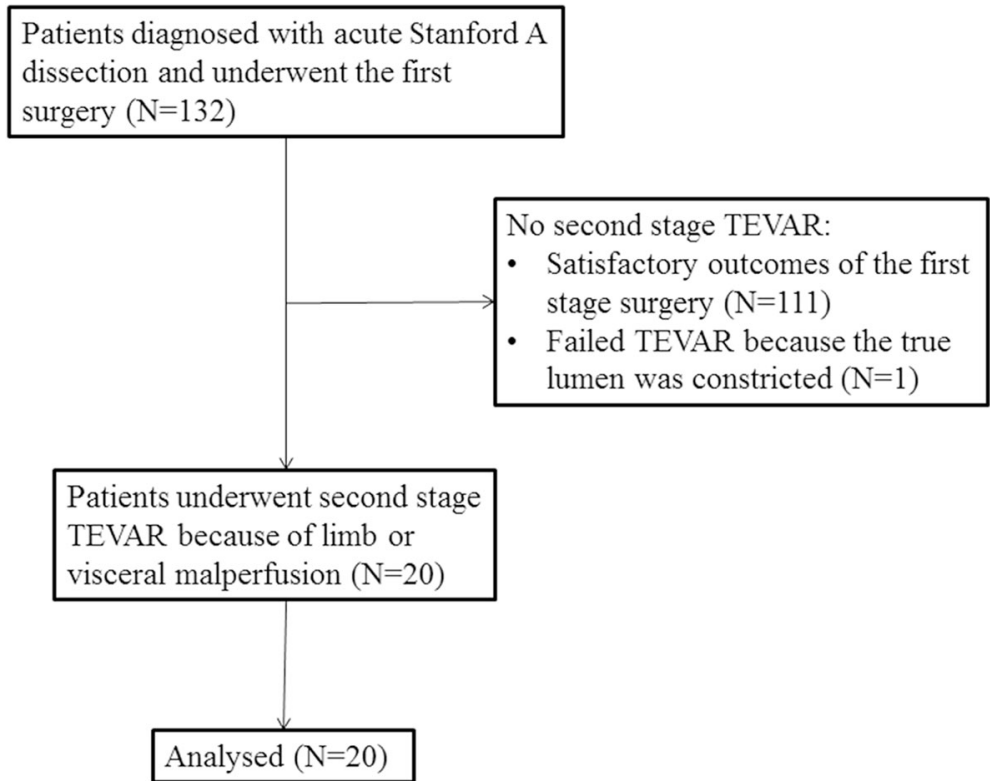

Fig. 1 A total of 132 patients with Stanford A aortic dissection underwent an open surgery. Twenty of them underwent second stage TEVAR because of limb or visceral malperfusion and were enrolled

performed. The ulcer was covered, and the malperfusion was resolved (Fig. 3b, c).

All patients underwent computed tomography. The true lumen was compressed by a huge false lumen before surgery at the carina (Fig. 4a) and celiac artery (Fig. 4b) levels. Thrombosis of the false lumen was observed around the elephant trunk at the carina and celiac artery levels 1 month after the first stage surgery (Fig. 4v). Three months after TEVAR, false lumen thrombosis was resorbed; in addition, the trunk was fully expanded at the carina level, and the true lumen was enlarged at the celiac artery level (Fig. 4e, f).

Table 1 Baseline characteristics

\begin{tabular}{ll}
\hline Characteristic & Two-stage hybrid aortic repair $(\boldsymbol{n = 2 0})$ \\
\hline Age (years) & $45.1 \pm 12.2$ \\
Gender, $\mathrm{n}(\%)$ & $11(55.0)$ \\
$\quad$ Male & $9(45.0)$ \\
$\quad$ Female & $26.2 \pm 4.8$ \\
BMl (kg/m ${ }^{2}$ ) & $16(80.0)$ \\
Hypertension, $\mathrm{n}(\%)$ & $12(60.0)$ \\
Smoking, $\mathrm{n}(\%)$ & $212.3 \pm 57.1$ \\
Total bypass time (min) & $26.2 \pm 18.7$ \\
Arrest time (min) & $493.6 \pm 79.2$ \\
Operative time (min) & $102.6 \pm 39.3$ \\
Ventilation time (h) &
\end{tabular}

BMI Body mass index
The aortic data at the celiac artery level are displayed in Table 3. The true lumen was not enlarged enough after the first surgery. After TEVAR, substantial improvement was noted. The true lumen index increased to $56.8 \pm 10.9 \%(P<0.05$ compared to the value after the first surgery).

\section{Discussion}

Hybrid techniques for the treatment of Stanford A dissection are increasingly applied. Type III hybrid procedure has its own advances in patients with one or more entry tears in distal descending aorta. It was reported that $20-40 \%$ of patients require TEVAR to the descending aorta for the repair of Stanford A aortic dissection because of a small true lumen in the distal aorta, with or without malperfusion [22]. In the present case series, 20 patients underwent TEVAR about 1 month after the first operation. The results showed that second stage TEVAR was effective for descending aorta remodeling, with increased true lumen index and decreased false lumen index. In addition, it was effective in treating malperfusion. Limbs and visceral perfusion recovered well after TEVAR.

We performed TEVAR in the second stage surgery in all patients. The thrombosis in the false lumen was resorbed, and the true lumen might be enlarged about 1 month after the central procedure. Meanwhile, the incidence of paraplegia may increase if the patient underwent central surgery and 
Table 2 TEVAR information of the patients

\begin{tabular}{|c|c|c|c|c|c|}
\hline No. & Gender & Age (years) & Reason for TEVAR & Stent in TEVAR & Surgery interval \\
\hline 1 & Male & 35 & Narrow true lumen, limbs malperfusion & Microport 2,624,160 & 1 month \\
\hline 2 & Female & 42 & Narrow true lumen, limbs malperfusion & Microport 2,826,160 & 1 month \\
\hline 3 & Male & 33 & Narrow true lumen, limbs malperfusion & Microport 2,624,160 & 1 month \\
\hline 4 & Male & 40 & Narrow true lumen, visceral malperfusion & Relay $2,826,170$ & 1 month \\
\hline 5 & Male & 38 & Narrow true lumen, visceral malperfusion & Microport 2,624,160 & 1 month \\
\hline 6 & Male & 60 & Raising distal part of the stented elephant trunk, limbs malperfusion & Microport 3,026,160 & 2 weeks \\
\hline 7 & Male & 51 & Narrow true lumen, limbs malperfusion & Microport 2,624,160 & 1 month \\
\hline 8 & Female & 45 & Narrow true lumen, visceral malperfusion & Microport 2,624,160 & 1 month \\
\hline 9 & Female & 38 & Narrow true lumen, visceral malperfusion & Microport 2,624,160 & 1 month \\
\hline 10 & Female & 42 & Narrow true lumen, visceral malperfusion & Microport 2,826,160 & 1 month \\
\hline 11 & Female & 45 & Narrow true lumen, limbs malperfusion & Microport 2,624,160 & 1 month \\
\hline 12 & Female & 31 & Narrow true lumen, limbs malperfusion & Microport 2,826,160 & 3 weeks \\
\hline 13 & Female & 28 & Narrow true lumen, limbs malperfusion & Microport 2,624,160 & 3 weeks \\
\hline 14 & Male & 31 & Endoleak at distal part of the stent, visceral malperfusion & Microport 2,826,160 & 1 month \\
\hline 15 & Male & 48 & Narrow true lumen, visceral malperfusion & Microport 2,826,160 & 1 month \\
\hline 16 & Male & 43 & Narrow true lumen, visceral malperfusion & Microport 2,826,160 & 3 weeks \\
\hline 17 & Male & 71 & Narrow true lumen, visceral malperfusion & Microport 2,826,160 & 3 weeks \\
\hline 18 & Male & 53 & Narrow true lumen, visceral malperfusion & Microport 2,826,160 & 1 month \\
\hline 19 & Female & 62 & Narrow true lumen, visceral malperfusion & Microport 2,624,160 & 1 month \\
\hline 20 & Female & 66 & Narrow true lumen, visceral malperfusion & Microport 2,826,160 & 1 month \\
\hline
\end{tabular}

TEVAR simultaneously. Based on our clinical experience, a 1-month period is a good timing for TEVAR after the first surgery, with good thrombosis outcomes because the aortic intima is not yet stable. Waiting for a long time after the first surgery might lead to difficulties such as narrowing of the true lumen.
In addition, open surgery has some limitations [23]. First, the elephant trunk is not long enough for some patients. Secondly, in some complex cases, it could be inserted into the wrong place of the descending aorta, especially in case of first entry tears at the arch and descending part of the aorta. In one case in this series, the elephant trunk was inserted

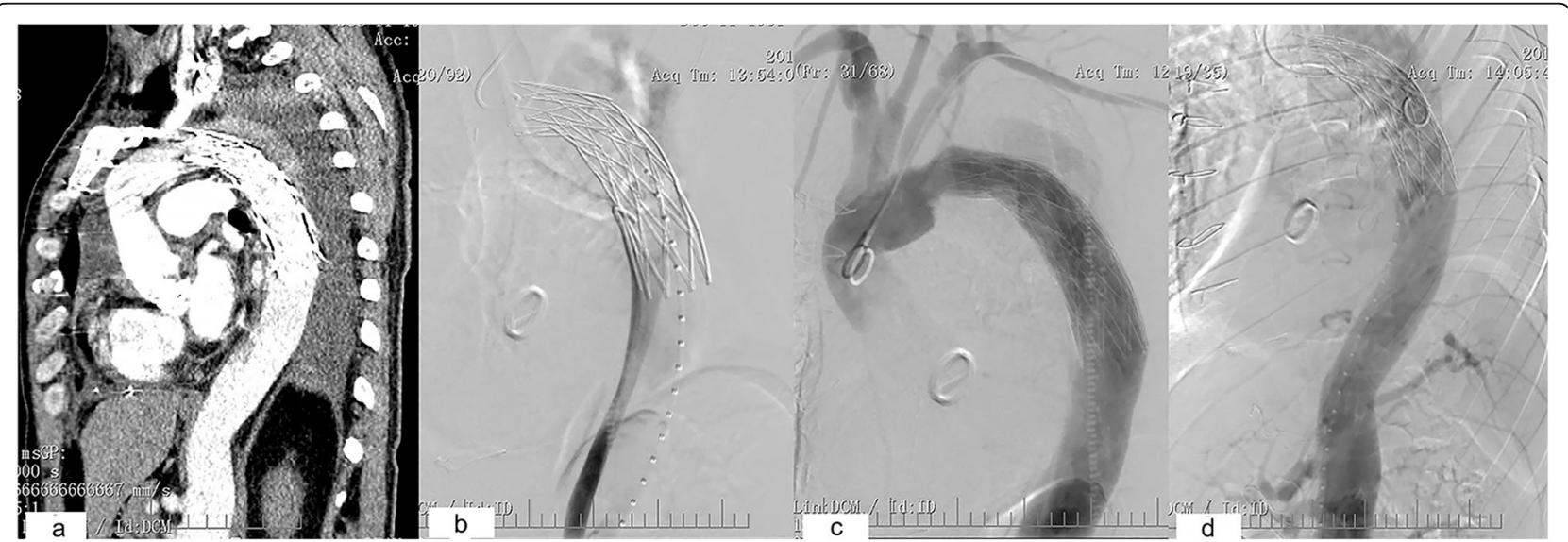

Fig. 2 a The elephant trunk was found in the wrong place based on CT. $\mathbf{b}$ In the angiography of the femoral artery, the true lumen was constricted and very small. c Trunk in the false lumen. $\mathbf{d}$ The blood supply of abdominal organs was from the false lumen 


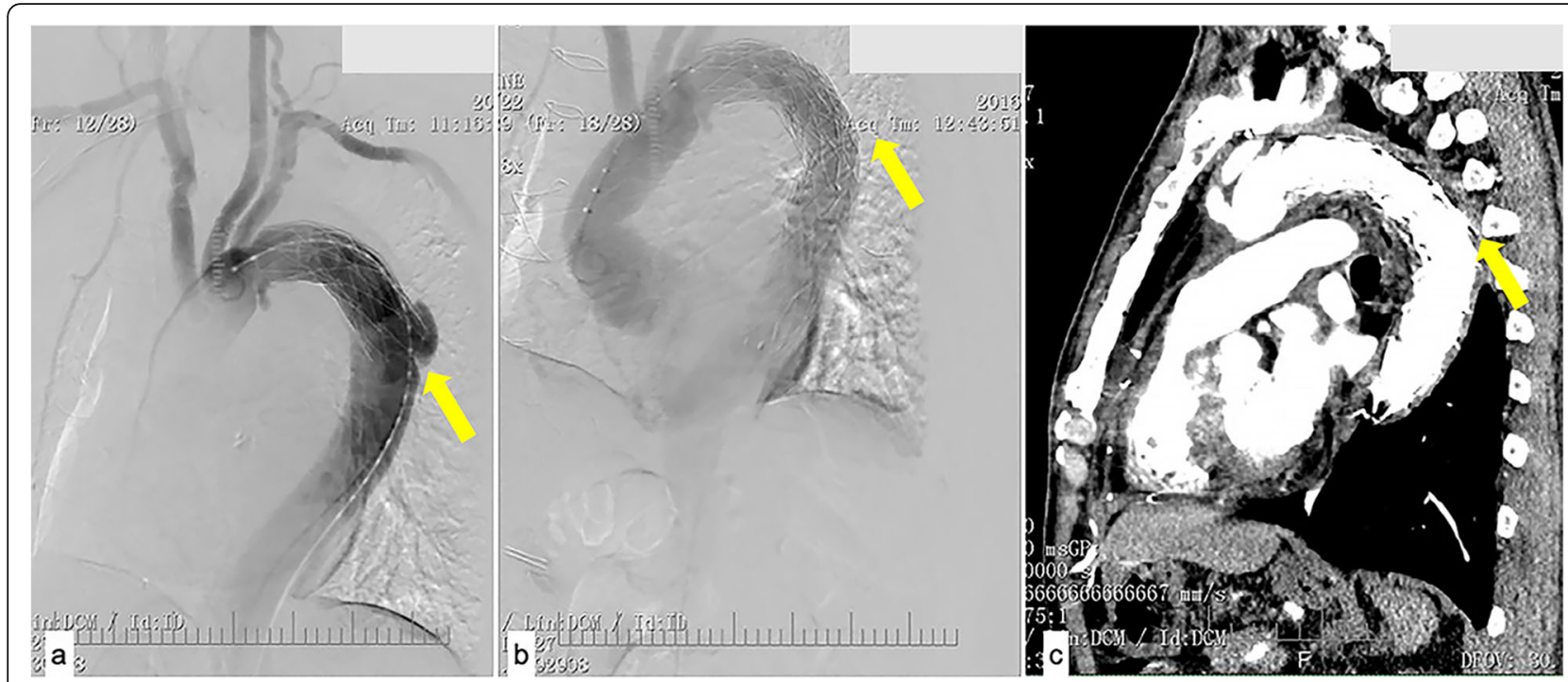

Fig. 3 a Angiography illustrating that the distal part of the elephant trunk was raised to an ulcer of the descending aorta. b Second-stage TEVAR covered the ulcer. c At one-month follow-up, aorta remodeling was efficient

into the false lumen. In another patient, the distal part of the trunk was placed in the ulcer of the descending aorta. Compared with conventional repair, the hybrid approach could be safer for complex conditions, because of a wire from the femoral artery to the arch. This could ensure the surgeon inserts the stent into the true lumen by angiography. In addition, the hybrid surgery results in $80-100 \%$ of false lumen thrombus formation in proximal descending aorta (stented segment) [24-26].

The most common reasons for TEVAR in aortic dissection are endoleak, false lumen perfusion, and aortic dilatation $[27,28]$. In the present case series, the indications for TEVAR were narrow true lumen, limb malperfusion, and visceral malperfusion. Additional studies are necessary to examine the risk factors for TEVAR after open repair of type A aortic dissection. The true lumen index represents the area of an aortic section providing blood to the distal organs, and could be considered a good indicator of organ and limb perfusion [29], indicating the need for TEVAR to increase this parameter. Indeed, a narrow true lumen and a low true lumen index are subsequent to false lumen perfusion, since elevated false lumen perfusion leads to reduced true lumen perfusion. As shown in the present study, the true lumen index was only marginally increased after the first surgery, but increased more significantly after TEVAR. At our center, we use the true lumen index to evaluate the status of distal aortic remodeling. However, the need for TEVAR is based on a comprehensive assessment of blood supply to the distal organs.

Nevertheless, TEVAR is not without risk, including spinal cord injury $[18,30]$, probably by covering the main vessels feeding the spinal cord. Therefore, the endografts used in second stage-TEVAR are shorter than those in Stanford B dissection. In the current cases, most endografts were $160 \mathrm{~mm}$ in length, and were placed above the celiac artery level to preserve blood flow to abdominal organs.

The present study had some limitations. It was a retrospective observational study with potential selection bias. The sample size was small for patients administered TEVAR, and follow-up was short. The study population was young, and it should be evaluated whether this approach would be valuable in older and elderly patients. Nevertheless, aortic dissection occurs at a younger age in China than in Western countries [30].

\section{Conclusions}

In conclusion, two-stage TEVAR at the residual true lumen in the distal aorta after initial surgery for Stanford A aortic dissection is effective in distal aorta remodeling at about 1 month after the first operation. In addition, it is useful for treating malperfusion. The above results suggest that this approach has low operative morbidity and mortality. The hybrid two-stage repair may be a good option for patients suffering from Stanford A 

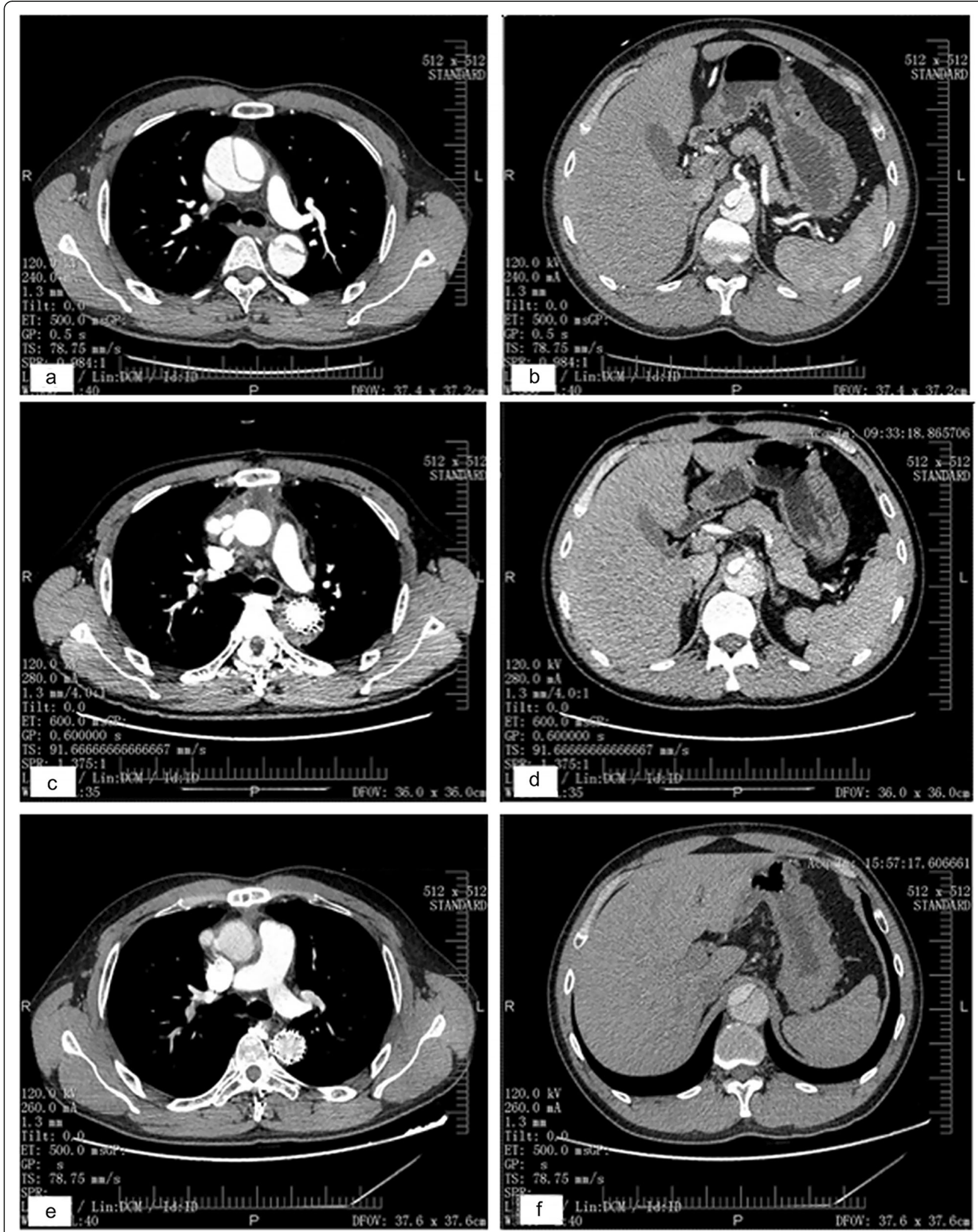

Fig. 4 After Stanford A dissection, the true lumen was compressed by a huge false lumen before surgery at the carina (a) and celiac artery (b) levels. Thrombosis of the false lumen was observed around the stented graft at the carina (c) and celiac artery (d) levels 1 month after the first operation. TEVAR was performed and 3 months later, false lumen thrombosis was resorbed; in addition, the elephant trunk was fully expanded at the carina level (e), and the true lumen was enlarged at the celiac artery level (f) 
Table 3 Aortic data at the celiac artery level

\begin{tabular}{|c|c|c|c|c|c|c|}
\hline Variable & $\begin{array}{l}\text { Before } \\
\text { surgery }\end{array}$ & $\begin{array}{l}1 \text { month after the first } \\
\text { surgery }\end{array}$ & $\begin{array}{l}3 \text { months after } \\
\text { TEVAR }\end{array}$ & $\begin{array}{l}6 \text { months after } \\
\text { TEVAR }\end{array}$ & $\begin{array}{l}12 \text { months after } \\
\text { TEVAR }\end{array}$ & 24 months after TEVAR \\
\hline $\begin{array}{l}\text { True lumen } \\
(\mathrm{mm})\end{array}$ & $10.2 \pm 2.4$ & $12.2 \pm 2.9^{a}$ & $17.6 \pm 4.5^{\mathrm{ab}}$ & $19.1 \pm 3.6^{\mathrm{abc}}$ & $21.2 \pm 4.4^{\mathrm{abc}}$ & $22.1 \pm 5.8^{\mathrm{abc}}$ \\
\hline $\begin{array}{l}\text { False lumen } \\
(\mathrm{mm})\end{array}$ & $17.8 \pm 2.9$ & $16.1 \pm 3.5^{\mathrm{a}}$ & $13.6 \pm 4.1^{\mathrm{ab}}$ & $11.2 \pm 2.1^{a b c}$ & $10.1 \pm 3.5^{\mathrm{abc}}$ & $9.4 \pm 5.5^{\mathrm{abc}}$ \\
\hline $\begin{array}{l}\text { True lumen } \\
\text { index (\%) }\end{array}$ & $37.1 \pm 6.4$ & $43.4 \pm 9.1^{a}$ & $56.8 \pm 10.9^{\mathrm{ab}}$ & $63.1 \pm 9.8^{\mathrm{abc}}$ & $67.3 \pm 10.1^{\mathrm{abc}}$ & $69.1 \pm 11.2^{\mathrm{abc}}$ \\
\hline
\end{tabular}

a. vs. preoperative, $\mathrm{P}<0.05$

b. vs. 1 months after first surgery, $P<0.05$

c. vs. 3 months after re-intervention, $\mathrm{P}<0.05$

dissection with a small true lumen in the distal aorta and malperfusion. Simultaneously endografting the distal descending aorta could also be considered in complex cases. Further investigation of the safety and long-term efficacy of this method is warranted.

\section{Abbreviations}

TEVAR: Thoracic endovascular aortic repair; MRI: Magnetic resonance imaging; CPB: Cardiopulmonary bypass; SD: Standard deviation

\section{Acknowledgements}

Not applicable.

\section{Authors' contributions}

WZX and WMX conceived and supervised the study; ZXM and CBL performed clinical investigation; WZX and WJM analyzed the data; WZX and ZXM wrote the manuscript; WMX made manuscript revisions. All authors reviewed the results and approved the final version of the manuscript.

\section{Funding}

This study was funded by the National Natural Science Foundation of China (grant number 81600208 [Wang Z] and 81570256 [Wei M]), the Tianjin Municipal Science and Technology Commission (grant number 14ZCZDSY00023), the Medical Scientific Research Foundation of Guangdong Province of China (grant number A2018019), the Science and Technology project of Shenzhen of China (grant number JCYJ20180302173909492 [Wang Z] and JCYJ20180508152222104 [Wei M]) and the "Sanming" Project of Medicine in Shenzhen, P. R. China. The funders had no role in study design, data collection and analysis, decision to publish, or preparation of the manuscript.

\section{Availability of data and materials}

The datasets analyzed in the current study are available from the corresponding author upon reasonable request.

\section{Ethics approval and consent to participate}

This study was approved by the ethics committees of Fuwai Hospital Chinese Academy of Medical Sciences Shenzhen and Tianjin Medical University General Hospital. The need for individual consent was waived by the committees because of the retrospective nature of the study.

\section{Consent for publication}

Not applicable.

\section{Competing interests}

The authors declare that they have no competing interests.

\section{Author details}

${ }^{1}$ Department of Cardiac Surgery, Fuwai Hospital Chinese Academy of Medical Sciences, Shenzhen, Guangdong, People's Republic of China. ${ }^{2}$ Department of Cardiac Surgery, The University of Hong Kong - Shenzhen Hospital, Shenzhen, Guangdong, People's Republic of China. ${ }^{3}$ Department of
Intensive Care, Fuwai Hospital Chinese Academy of Medical Sciences, Shenzhen, Guangdong, People's Republic of China.

Received: 21 April 2020 Accepted: 17 September 2020

Published online: 24 September 2020

\section{References}

1. Erbel R, Aboyans V, Boileau C, Bossone E, Bartolomeo RD, Eggebrecht $H$ et al. 2014 ESC guidelines on the diagnosis and treatment of aortic diseases: document covering acute and chronic aortic diseases of the thoracic and abdominal aorta of the adult. The task force for the diagnosis and treatment of aortic diseases of the European Society of Cardiology (ESC). Eur Heart J. 2014;35:2873-926.

2. Goldfinger JZ, Halperin JL, Marin ML, Stewart AS, Eagle KA, Fuster V. Thoracic aortic aneurysm and dissection. J Am Coll Cardiol. 2014:64:1725-39.

3. Pape LA, Awais M, Woznicki EM, Suzuki T, Trimarchi S, Evangelista A, et al. Presentation, diagnosis, and outcomes of acute aortic dissection: 17-year trends from the international registry of acute aortic dissection. J Am Coll Cardiol. 2015:66:350-8.

4. Howard DP, Banerjee A, Fairhead JF, Perkins J, Silver LE, Rothwell PM, et al. Population-based study of incidence and outcome of acute aortic dissection and premorbid risk factor control: 10-year results from the Oxford vascular study. Circulation. 2013;127:2031-7.

5. Chiu P, Tsou S, Goldstone AB, Louie M, Woo YJ, Fischbein MP. Immediate operation for acute type a aortic dissection complicated by visceral or peripheral malperfusion. J Thorac Cardiovasc Surg. 2018;156:18-24 e3.

6. Cho K, Jeong J, Park J, Yun S, Woo J. Long-term changes in the distal aorta after aortic arch replacement in acute DeBakey type I aortic dissection. Korean J Thorac Cardiovasc Surg. 2016;49:264-72.

7. Crawford TC, Beaulieu RJ, Ehlert BA, Ratchford EV, Black JH 3rd. Malperfusion syndromes in aortic dissections. Vasc Med. 2016;21:264-73.

8. Berretta P, Trimarchi S, Patel HJ, Gleason TG, Eagle KA, Di Eusanio M. Malperfusion syndromes in type a aortic dissection: what we have learned from IRAD. J Vis Surg. 2018:4:65.

9. Tanaka A, Sandhu HK, Estrera AL. Descending endografts for type a dissections: con. Ann Cardiothorac Surg. 2016;5:227-32.

10. Katayama K, Uchida N, Katayama A, Takahashi S, Takasaki T, Kurosaki T, et al. Multiple factors predict the risk of spinal cord injury after the frozen elephant trunk technique for extended thoracic aortic disease. Eur $J$ Cardiothorac Surg. 2015;47:616-20.

11. Makaroun MS, Dillavou ED, Kee ST, Sicard G, Chaikof E, Bavaria J, et al. Endovascular treatment of thoracic aortic aneurysms: results of the phase II multicenter trial of the GORE TAG thoracic endoprosthesis. J Vasc Surg. 2005;41:1-9.

12. Bavaria JE, Appoo JJ, Makaroun MS, Verter J, Yu ZF, Mitchell RS, et al. Endovascular stent grafting versus open surgical repair of descending thoracic aortic aneurysms in low-risk patients: a multicenter comparative trial. J Thorac Cardiovasc Surg. 2007:133:369-77.

13. Matsumura JS, Cambria RP, Dake MD, Moore RD, Svensson LG, Snyder S, et al. International controlled clinical trial of thoracic endovascular aneurysm repair with the zenith TX2 endovascular graft: 1-year results. J Vasc Surg. 2008:47:247-57 discussion 57.

14. Stone DH, Brewster DC, Kwolek CJ, Lamuraglia GM, Conrad MF, Chung TK, et al. Stent-graft versus open-surgical repair of the thoracic aorta: mid-term results. J Vasc Surg. 2006;44:1188-97. 
15. Walsh SR, Tang TY, Sadat U, Naik J, Gaunt ME, Boyle JR, et al. Endovascular stenting versus open surgery for thoracic aortic disease: systematic review and meta-analysis of perioperative results. J Vasc Surg. 2008;47:1094-8.

16. Leshnower BG, Szeto WY, Pochettino A, Desai ND, Moeller PJ, Nathan DP, et al. Thoracic endografting reduces morbidity and remodels the thoracic aorta in DeBakey III aneurysms. Ann Thorac Surg. 2013;95:914-21.

17. Vallabhajosyula P, Szeto W, Desai N, Bavaria JE. Type I and type II hybrid aortic arch replacement: postoperative and mid-term outcome analysis. Ann Cardiothorac Surg. 2013;2:280-7.

18. Tokuda Y, Oshima H, Narita Y, Abe T, Araki Y, Mutsuga M, et al. Hybrid versus open repair of aortic arch aneurysms: comparison of postoperative and mid-term outcomes with a propensity score-matching analysis. Eur J Cardiothorac Surg. 2016;49:149-56.

19. Sun L, Qi R, Zhu J, Liu Y, Zheng J. Total arch replacement combined with stented elephant trunk implantation: a new "standard" therapy for type a dissection involving repair of the aortic arch? Circulation. 2011;123:971-8.

20. Manetta F, Newman J, Mattia A. Indications for thoracic EndoVascular aortic repair (TEVAR): a brief review. Int J Angiol. 2018;27:177-84.

21. Grabenwoger M, Alfonso F, Bachet J, Bonser R, Czerny M, Eggebrecht H, et al. Thoracic endovascular aortic repair (TEVAR) for the treatment of aortic diseases: a position statement from the European Association for CardioThoracic Surgery (EACTS) and the European Society of Cardiology (ESC), in collaboration with the European Association of Percutaneous Cardiovascular Interventions (EAPCI). Eur Heart J. 2012;33:1558-63.

22. Omura A, Miyahara S, Yamanaka K, Sakamoto T, Matsumori M, Okada K, et al. Early and late outcomes of repaired acute DeBakey type I aortic dissection after graft replacement. J Thorac Cardiovasc Surg. 2016;151:341-8.

23. Sun L, Li M, Zhu J, Liu Y, Chang Q, Zheng J, et al. Surgery for patients with Marfan syndrome with type a dissection involving the aortic arch using total arch replacement combined with stented elephant trunk implantation: the acute versus the chronic. J Thorac Cardiovasc Surg. 2011;142:e85-91.

24. Iribarne A, Keenan J, Benrashid E, Wang H, Meza JM, Ganapathi A, et al. Imaging surveillance after proximal aortic operations: is it necessary? Ann Thorac Surg. 2017;103:734-41.

25. Shi E, Gu T, Yu Y, Wang C, Yu L, Fang Q, et al. Simplified total arch repair with a stented graft for acute DeBakey type I dissection. J Thorac Cardiovasc Surg. 2014;148:2147-54

26. Katayama A, Uchida N, Katayama K, Arakawa M, Sueda T. The frozen elephant trunk technique for acute type a aortic dissection: results from 15 years of experiencedagger. Eur J Cardiothorac Surg. 2015;47:355-60 discussion 60

27. Zhang L, Zhao Z, Chen Y, Sun Y, Bao J, Jing Z, et al. Reintervention after endovascular repair for aortic dissection: a systematic review and metaanalysis. J Thorac Cardiovasc Surg. 2016;152:1279-88 e3.

28. Faure EM, Canaud L, Agostini C, Shaub R, Boge G, Marty-ane C, et al. Reintervention after thoracic endovascular aortic repair of complicated aortic dissection. J Vasc Surg. 2014;59:327-33.

29. Patterson BO, Cobb RJ, Karthikesalingam A, Holt PJ, Hinchliffe RJ, Loftus IM, et al. A systematic review of aortic remodeling after endovascular repair of type $B$ aortic dissection: methods and outcomes. Ann Thorac Surg. 2014;97:588-95.

30. He X, Liu W, Li Z, Liu X, Wang T, Ding C, et al. Hybrid approach to Management of Complex Aortic Arch Pathologies: a single-center experience in China. Ann Vasc Surg. 2016;31:23-9.

\section{Publisher's Note}

Springer Nature remains neutral with regard to jurisdictional claims in published maps and institutional affiliations.

Ready to submit your research? Choose BMC and benefit from:
- fast, convenient online submission
- thorough peer review by experienced researchers in your field
- rapid publication on acceptance
- support for research data, including large and complex data types
- gold Open Access which fosters wider collaboration and increased citations
- maximum visibility for your research: over 100M website views per year
At BMC, research is always in progress.
Learn more biomedcentral.com/submissions

